\title{
A Survey of Studies on Sociopragmatic Use of Linguistic Politeness with Special Focus on Hindi and Japanese
}

\author{
N. Kumari
}

\begin{abstract}
The present study discusses the theories, methods and results of the available literature in the area of linguistic politeness involving i) the use of indirectness and honorifics as politeness strategies, ii) the notion of 'face' as a social image, other social factors and social structure that affect the use of and variation in linguistic forms, and iii) the historical reasons for the emergence of stereotypes in the use of linguistic politeness in a society. The first section discusses the studies based on data from a single language. The second section focus on the studies on Hindi and on Japanese, respectively. The third section describes the work done in cross-cultural studies in politeness. The fourth section describes the research gap that emerges from the discussions in the available literature.
\end{abstract}

Index Terms-Hindi, Japanese, politeness, sociopragmatics.

\section{INTRODUCTION}

A major group of researchers have focused on the use of linguistic forms and their correlation with social indexing in the language community. These studies give us insights into the sociopragmatic aspect of the use of language and the manner in which the use and variation in the use of linguistic forms reflect the changes in the society. As each language has its own cultural milieu, the global and local changes in the society induce changes in the use of linguistic politeness as well. Even though there is considerable amount of research work in the area of cross-cultural studies, there is a vast patch to be filled by more comparative and contrastive studies. Focusing on a comparison of sociopragmatic variation in the use of linguistic politeness, in two or more languages, with particular focus on Hindi and Japanese as two languages from an Asian community, the paper presents the findings of available literature and the potential research gaps.

The available literature on the sociopragmatic aspect of the use of linguistic politeness includes a description of the use of linguistic forms, historical reasons for the variation in and emergence of some new forms in relation to modernization and standardization of the languages, as well as a description of the changes occurring in society leading to the variation in the use of these linguistic forms. The present study discusses the theories, methods and results of the available literature in the area of linguistic politeness involving i) the use of indirectness and honorifics as politeness strategies, ii) the notion of 'face' as a social image, other social factors and social structure that affect the use of and variation in linguistic forms, and iii) the historical reasons for the emergence of stereotypes in the use of

Manuscript received October 2, 2015; revised December 13, 2015.

N. Kumari is with the University of Tsukuba, Japan (e-mail: rosynivi4@gmail.com). linguistic politeness in a society. The first section discusses the studies based on data from a single language. The second section focus on the studies on Hindi and on Japanese, respectively. The third section describes the work done in cross-cultural studies in politeness. The fourth section describes the research gap that emerges from the discussions in the available literature.

\section{StUdies ON A Single LANGUAGE}

\section{A. Studies on the Use of Politeness in Hindi}

The author in [1] describes verbalization of respect in Hindi. Based on the data from native speaker judgment and from Hindi short stories, the author describes the use of titles and suffixes used with nouns; neutral, humble and exalting forms of verbs; the plurals of pronouns and verbs used to show respect to an addressee and a referent. The paper explains how the choice of one linguistic form over the other is not only grammatical but also sociolinguistic. [1] calls this use of honorific pronoun aap 'you honorific'with non-honorific verb do 'give' as 'progressive,' in the sense that it is used with a person of higher status but in intimate situations. The author explains that such constructions fulfill the '.... need for something that lies between aap and tum.' Examples 2a)-2c) illustrate this difference. On the one hand, 2a) and 2b) follow the norms of honorification. On the other hand, 2c) flouts the rule and features as a form that lies between the two forms of use, non-honorific 2a), and honorific $2 b)$.

$\begin{array}{lll}\text { 2a) } & \text { tum } & \text { do. } \\ & \text { you } & \text { give.PRES } \\ \text { 'You give.' } & \text { aap } & \\ & \text { you. HON } & \text { dijiye. } \\ \text { 'You give.' } & \text { give. HON } \\ \text { 2c) } & \begin{array}{l}\text { aap } \\ \text { you. HON } \\ \end{array} & \text { do. } \\ & \text { 'You give.' } & \text { give.PRES }\end{array}$

The author attributes the use of this novel form to the influence of Panjabi on Hindi, as many speakers in Delhi are Panjabi-Hindi bilinguals (Panjabi does not have honorific verb forms like dijiye 'give.HON' in Hindi). However, the author in [1] admits that 'the real cause for this change is social...for we find this change even in areas where there are no Panjabi speakers.' The author emphasizes that the use of forms like 2c) '.. are fulfilling a linguistic need in which changing social relationship is being expressed linguistically.' Use of this form represents a need for a less formal, yet respectful form, in an asymmetrical relationship. 
The author in [2] describes the use of terms of address and second person pronominals in Hindi based on the dialogues in four popular Hindi novels written by a well-known literary artist, Munshi Premchand. The author shows that the use of these terms correlates with social status, caste attitude, and familial relations of the interactants. The study concludes that the asymmetry in society is reflected in the use of the terms of address and second person pronominals. For example, a person from the upper caste in society, or the father in a family can choose to use any of the three second person pronominals, whereas, a person from a lower caste or other members of the family always address a person from the upper caste and one's father, respectively, with honorific forms only. The author says in [2] that 'this static relationship is observed more in older generation than in younger generation.' The author concludes by saying that the novels taken for the study present a picture of the society in the 1930s in North India, and reflect subtle changes brought about in the society with the end of the zamindari system (where only zamindars who belonged to the upper caste held the land and made their tenants their farm labourers, who worked in their fields all their lives to pay their rent). Only with this change, people from the lower caste became more stable economically and earned respectable jobs and social living. Such economically well off people, even if they belonged to lower castes, were addressed with the honorific forms of second person pronominals. This brought changes in the way people from the upper caste addressed them. The terms used within the family, however, did not change much, as shown in the novels.

The authors in [3] cite the discussions on the hierarchy of the degree of politeness of the five syntactic structures in Hindi (imperative, optative, 'should' construction, simple present and passive) as discussed in [4] and argue that the hierarchy of different syntactic structures depends on as in [3] "the social context of a sentence in terms of role relationship between the participants," "social meaning of the structure," and "whether the benefit of the acts flows to the speaker or the hearer or whether it is neutral." The use of passive and imperative sentence structures are taken as an example, because in isolation a passive construction is considered to be more polite as it does not necessarily mention the agent of the action. An imperative construction, on the other hand, sounds like a command to the hearer and hence, is not polite. In order to test the degree of politeness of syntactic structures in different contexts, the authors framed the sentences for each of the following four contexts:

1) Conveying prohibition of certain behaviour on the part of the hearer

2) Asking the hearer to do something which is of benefit to the speaker

3) Asking the hearer to do something which is of benefit to the hearer

4) Stating something which is neutral to the other three contexts

All the syntactic forms in each of the contexts above were ranked by native speakers based on their judgment as to which forms are more polite than the other. Sentence $2 \mathrm{~d}$ ) illustrates a passive sentence construction and its politeness in context $\mathrm{A}$ as in [3].

$\begin{array}{lllll}\text { 2d) caaya } & \text { aise } & \text { nahiin pii } & \text { jaatii } \\ \text { tea } & \text { thus } & \text { NEG drink }\end{array}$

'Tea is not taken like this.'

The use of prohibitive passive does not sound polite to the informants and the authors suggest that because this construction is used in a prohibitive context, it suggests an implicature for strong censorship. Hence, even though it is indirect as it does not address the hearer directly, this expression is not considered to be polite. Similarly, an imperative construction, that is generally considered to be the most direct form and hence the least polite, sounds more polite than passive constructions in context $\mathrm{B}$ and $\mathrm{C}$. Sentences 2e) and 2f) are examples of imperative and passive sentences for context $B$ and $2 \mathrm{~g}$ ) and $2 \mathrm{~h}$ ) are for context $\mathrm{C}$, respectively as in [3].

Context B:

- Imperative

$\begin{array}{lll}\text { 2e) ye kaam } & \text { kar dijiye } & \text { taakii/ } \\ \text { this work } & \text { do+HON } & \text { so that/ } \\ \text { merii zindagii ban } & \text { jaaye. } \\ \text { my life } & \text { made } & \text { is. } \\ \text { 'Do this work (for me) so that my life is m }\end{array}$

'Do this work (for me) so that my life is made.'

- Passive

\begin{tabular}{lllll} 
2f) ye kaam & \multicolumn{2}{c}{ kar diyaa } & jaaye/ & \\
this work & \multicolumn{2}{c}{ do+PERF } & PASS so/ \\
taakii & merii & zindagii & ban & jaaye. \\
that & my & life & made & is.
\end{tabular}

'This work done is to be done (by you) so that my life is made.'

Context C:

- Imperative

$\begin{array}{llll}2 \mathrm{~g}) & \begin{array}{l}\text { ye } \\ \text { this davaa }\end{array} \text { medicine eat+HON } & \text { taakii/ } \\ \text { tabiyat thiik } & \text { ho that/ } \\ \text { condition cured } & \text { happens. }\end{array}$

'Have this medicine so that (you) get well.'

- Passive

\begin{tabular}{llll} 
2h) ye & davaa & kha lii & \multicolumn{2}{c}{ jaaye } \\
this & medicine & eat+HON PASS so \\
taakii & tabiyat & thiik ho jaye. \\
that & condition & cured happen
\end{tabular}

'This medicine is to be taken so that (you) get well.'

The findings show that for both the contexts, the use of a passive construction was considered to be less polite, irrespective of whether the benefit of what the speaker says flows to the speaker or the hearer. The reason that the authors suggest for this is the implicature in the passive constructions that the hearer must act as per the speaker's wishes. An imperative, however, does not have this implicature and thus, is considered to be more polite than passive sentences. However, in context D, where the cost-benefit scale was neutral, some informants found the passive to be the most polite form, unlike in other contexts where the use of passive was considered to be less polite. 
2i)

$\begin{array}{lll}\text { ye } & \text { kaam } & \text { kijiye } \\ \text { this } & \text { work } & \text { do+HON }\end{array}$

2j)

'Do this work.'

ye kaam kiyaa jaaye

this work do+PERF PASS

'Let's get this work done.'

Similarly, the authors explain the variation in the hierarchy of the syntactic forms based on the social meaning of these forms and not in an isolated linguistic context.

The authors in [5] show that the use of second person pronominals in Hindi is complex and cannot be described using the two-dimensional framework involving the concepts of 'power' and 'solidarity'. They in [5] argue that the use of personal pronouns and their meaning change "in accordance with their communication matrices." The authors describe various factors influencing the use of pronominals in Hindi including, family bond, difference of generation, place of origin, frequency of contact, relative age, sex, ceremonial ties, context of the encounter, shared activities or interests of the interactants, and education. The paper only explains the relevance of all of these factors by illustrating the use of pronominals, which gives a holistic picture of variation in the use of second person pronominals in Hindi, but does not focus on any one of these factors. However, the main result of the study [5] shows that, over the years, there has been 'a general shifting from asymmetrical to symmetrical pronoun usage'. This change is attributed to 'a greater uniformity of educational opportunity, increasing mutual respect and understanding and decreasing class divisions, all of which contribute to a sense of equality in society.'

\section{B. Summary}

The discussion in the literature suggests that the use of honorifics morpho-lexically and morpho-syntactically, shows the emergence of novel forms of subject-verb agreement in Hindi, in which the honorific form of a pronoun is used with a non-honorific form of a verb. This implicates a change in the use of agreement in order to convey a medium level of politeness and a change in the asymmetrical society of India. The use of other morpho-syntactic forms like passive, imperative, declarative and the degree of politeness varying as per the context are discussed. However, these studies do not focus on a particular variable in detail nor do they support this change with a study on intergenerational variation in the use of these forms. Most studies are descriptive in nature and are based on native speaker judgment on the politeness of expressions in Hindi by the author himself/herself or by a few respondents. There is a need for a larger scale study, which elicits the expressions from native speakers and is not just constructed by the author. This method is required to understand the actual use of linguistic politeness in Hindi.

Though the authors in [3] make use of the pragmatic theory of speech acts to illustrate the variation in the social meaning of linguistic forms as per the context, the available literature does not discuss the use of (in) directness in the use of linguistic politeness in Hindi. Built on the notion of speech acts and the use of illocutionary force in Hindi, the inclusion of linguistic forms that show (in) directness in
Hindi are required for a better understanding of the use of linguistic politeness in the language. In order to facilitate a cross-cultural study, both (in) directness and honorifics need to be included because not all languages in the world have an inbuilt system of honorifics (a unique characteristic of a few languages), and the degree of (in) directness shows cultural variability when it correlates with the degree of politeness. The theories of politeness based on 'facework' have also not been applied to investigate the use of linguistic politeness in Hindi, which would again help understand the cultural variability in verbal politeness behaviour in the Hindi speaking community.

\section{Studies on the Use of Politeness in Japanese}

Reference [6], with the aim of simplifying the understanding of keigo in Japanese for second language learners, describes the problem with understanding the honorific system in Japanese by illustrating with the following sequence of forms (all, in this case, meaning 'Will (you) come?') [6]:

\section{2k) oideni narimasuka RESPECTFUL \\ 21) kimasuka POLITE \\ 2m) kuruka NON-POLITE, NORMAL \\ 2n) mairimasuka DEFERENTIAL \\ 2o) kurunoka PEJORATIVE}

The author explains that the problem of a leaner gets aggravated "when s/he encounters additional forms such as irrashaimasuka and kurunokai, and realizes that these forms also mean 'Do you come?'." The author provides a set of simple rules based on data from native speaker judgment. The author designs two scales: the formality - informality scale, and the neutral - humble - respectful scale. The results of the study show that formality and politeness scale need to be distinguished. However, there can be more than one expression for each of the levels of speech. A balance in the use of forms on these two scales is acceptable when a conversation is between a speaker and a hearer but when referring to a third person, any combination of these two scales is acceptable. In order to facilitate the teaching of honorifics in Japanese, the author also gives a simple description of the use of these forms in daily life. This facilitates a better understanding of this complex system for the field of pragmatics as well.

The author in [7] uses the theoretical framework of [8] direct-indirect speech acts and justification from Gricean conversational maxims [9] to explain the use of conventional indirect forms kure/morae 'give-me/get-can' of requests in Japanese. The study builds on the distinction of the likes of 'Can you..?' and 'Are you able to...?' constructions in English as shown in [10] and [11] show that this distinction comes out when we investigate the use of interrogative forms of requests using kure/morae in Japanese. The study adds to the literature on the use of questions as request forms but focusses only on the ability questions that are used as requests, which are understood as conventional request forms. The paper shows the six tests used by [11] to distinguish the interrogatives that are both questions and requests (Group II) from the forms that are only questions (Group I), in Japanese [7]. 


\section{2p) kono mondai wakarimasu ka? (Group I) this problem understand INT 'Do you understand this problem?' 2q) hon o yonde kuremasen ka? (Group II) \\ book ACC read give.POT.NEG INT 'Won't you read the/a book?'}

The author contends that these tests fail to distinguish the two forms of questions as each one has contradictory instances of Japanese utterances. The author gives a better explanation for the choice (unlike earlier work where the reason of the choice was considered to be arbitrary) of Group II interrogatives as requests over Group I 'only questions.' The author shows that Group II forms 'kure/morae' do not [7] assume the willingness of the hearer, as yes-no questions, but leave scope for the hearer to say 'no.' However, since the use of Group II forms violates the conversational maxims, it triggers the implicature that the speaker mainly intends to be polite, by using these forms. In brief, the study gives a detailed description of the reason why an ability question becomes a conventional form of request and how these forms show politeness.

The author in reference [12] questions the 'universality' of linguistic politeness described in Brown and Levinson's framework [13]. The author argues that even though the framework leaves scope to incorporate the cultural variability of factors that influence politeness (relative power (P), social distance (D), and rank of imposition(R)), the constituent of 'face' also should be taken as a cultural variable to give a better theoretical account of the practical use of linguistic politeness in a given culture. The author reports examples of formulaic expressions and verbs for 'give' and 'receive' in Japanese that are shown to be used as a 'relation-acknowledging device.' Thus, these forms function as one of the positive politeness strategies as the use of these forms based on the social relationship of the interactants. This shows that Japanese does not fall under the group of cultures like American and European cultures where 'negative politeness' is said to be the most used strategy. The results suggest that even if negative politeness strategies are superficially used in Japanese, the underlying principle of its usage and the collectivist social culture of the speaker are different from that of western culture. In Japanese, the function of such forms is to acknowledge the social ranking of the interactants. According to the author, it does not function as one of the least imposing strategies that would avoid entry to the territory of an individual. The author gives strong evidence and presents an argument against the universality of the politeness theory based on 'face.'

The author in [14] investigates in what ways Japanese women, who use more honorifics and humble forms that show their powerlessness, resolve the conflict of giving directives when in a professionally powerful position. The study is based on three sets of data transcripts: 1) two boys' and two girls' cartoons; 2) two instructional (one cooking and one home repair show) television shows with the chief instructor as a female and a male, respectively; two detective shows in which one show has an all-women detective team (non-traditional occupation for women) and the other where the chief detective is a male and his sub-ordinates belong to both genders. The author examines imperatives, requests, desideratives, and a few declaratives that were used to give orders. The results of the investigation show that in the first and second data set, female speech had more honorifics and male speech had more direct imperatives. Male speech varied according to the relative status of the addressee but female speech used polite forms uniformly with all the addressees. The third data set showed that in non-traditional roles, females resolve the conflict of powerlessness in their language and power in their workplace by empowering their own speech and not defeminizing. The study investigates the use of instructional language with respect to the gender of the speaker. The results reemphasize the fact that females uniformly use polite forms even with subordinates and when giving orders, unlike male speakers. This result implicates a gender gap among Japanese speakers.

Reference [15] presents a genealogical account of the emergence of Japanese women's language. The author makes use of and discusses the language in the novels, newspapers, and magazines since the Meiji period. An account of the use of distinct forms of verb-endings by males and females is presented along with the description of the intricate evolution of the notions of nation-state, standard Japanese, economics of the popularity of print media and modernity in Japan. The data presented shows that on the one hand, female speech was standardized as a part of cultural and language ideology. On the other hand, the use of too many honorifics in female speech did not project Japanese females to be as smart as the western females, and as translating Japanese literature was difficult, the popular print-media was attracted by the language of school girls. Hence, the verb endings like, da-wa and no-yo considered to be vulgar in the earlier 19th century have become accepted and are used in the present times by the media. The discussion in the paper explains that the language of Japanese women has not emerged naturally but has been constructed simultaneously with the state formation, capitalist accumulation, capitalization and radical class reconfiguration. With the changing social, political and economic ideologies of the country, Japanese women's language has also changed. The study draws on the language used in late 19th century to early 20th century in literature and print media of Japan. It discusses the changes in Japanese women's language during this period.

Reference [16] presents the dilemma of categorizing the use of politeness in Japanese to be dictated by social norm or by the linguistic devices like honorifics used in a formulaic way. The author taking examples from [12] suggests that formulaic expressions like douzoyoroshikuonegaishimasu does not have the literal meaning "please take care (of me)" only but can also have a conventional meaning "pleased to meet you." The author argues that even these formulaic expressions are not mere single meaning devices as they change with the context and the social norm as per the context. Hence, these forms are also used as strategies and this makes Japanese no different from English in this case.

The authors in [17] argue that Brown and Levinson's [13] theory of face-saving of speaker and hearer explains the use 
of Japanese honorifics better than the notion of honorifics as 'relation-acknowledging devices' in [12] and 'discernment' in [18]. The authors use Japanese data from native speaker judgment and show exceptions to the two non-FTA (face-threatening acts) based theories, which are logically shown to be minimally explained using the formula of weightiness of FTA in Brown and Levinson's [13] theory, which is dependent on power, distance and degree of imposition of the act. The theory was supported over the two former theories based on five grounds: 1) It explains better the use of honorifics in a non-FTA situation, because if appropriate honorifics is not used in a situation, it leads to an FTA for the interactants; 2) The use of honorifics as per discernment theory is considered to be sociopragmatically obligatory but it cannot happen for all the situations. The exception is the Japanese example of sentence $2 r$ ).

\section{2r) senseega dookyuusei o o-koroshi-ninat-ta. teacher NOM classmate ACC kill.HON.PAST 'My teacher killed my classmate.'}

The use of honorifics in this situation is not acceptable; 3 ) Face theory explains the use of honorifics by superiors to an inferior in the power hierarchy due to a higher imposition of a request. For example, when a teacher asks for a very time-taking favour from a student, s/he uses a polite form with him/her. This does not sound unusual even though according to the theories based on relation-acknowledgement this cannot be explained; 4) The use and non-use of honorifics is attributed to the variation in distance variables. For example, in a meeting, professors use honorific forms, whereas in informal situations they do not use them; 5) It explains the importance of silence in front of a superior as a strategy of avoiding an FTA by not doing it at all. The study focusses on testing the universal theory of politeness based on 'face' and the findings show that when it comes to the use of Japanese honorifics, the theory explains it the best.

The author in [19] emphasizes the importance of looking at pragmatics also in a socio-historical perspective like anthropology. They draw on the western and Japanese theories of pragmatics and show that a historical account gives a better understanding of the scenario of language change pragmatically. Citing from literature discussing universality in general and modern Japanese native speaker judgment, the author emphasizes the importance of a historical perspective. The author discusses the theories in pragmatics, honorifics and social indexicality and shows how modern Japanese and the use of honorifics in Japanese reflect the historical aspect of the changes over the years.

The author discusses the significance of a study of linguistic data based on historical, social, and ideological creation and maintenance of linguistic forms by a national political process in Japan. The author criticizes linguists in their work for remaining unaware and blindly succumbing to modern nationalism, ahistoric universalism, and armchair rationalism. This, according to the author, would hide historic reality and just reflect a narrow-minded micro-social ideological horizon of (post-) modernity."

Reference [20] supports principles of face-saving politeness [13] and investigates its criticism by [12]. The author explains that even though the use of verbs for 'giving' and 'receiving' in Japanese are relation-acknowledging devices as suggested by the author in [12], the directionality of benefit is explained by face-saving politeness. Verb ageru 'give1' has a very constrained use as it involves positive politeness, as the benefit of the action flows from the speaker to the other, whereas, other forms kureru 'give 2' and morau 'receive,' involve negative politeness because the benefit flows from others to speaker and shows indebtedness of the speakers. Reference [20] supports Brown and Levinson's description of Japanese to be using more of negative politeness because according to the author they discuss the use of negative politeness strategy to be to 'go on record as incurring a debt.' The author quotes that "though in passing, point out that this strategy is likely to have special force in a society like Japan which is preoccupied with indebtedness," and affirms that the expressions like Verbs kureru and morau in Japanese do give importance to the speakers' indebtedness to the hearer.

The paper [21] focuses on the concepts of politeness manifest in Japanese business etiquette training in relation to the politeness theories in [13] and [18]. The results show that the training pays attention to both formal forms such as honorifics as well as verbal strategies as described in [13] along with the body language. All these forms are presented as the necessary social norms to sound polite. In [21] it is illustrated that if a flight attendant uses the following form of apology (2s) with a more polite verb itashimashita 'do' with a slight bow, it would be considered to be less polite than the use of shimashita 'do' (2t) with a deeper bow.

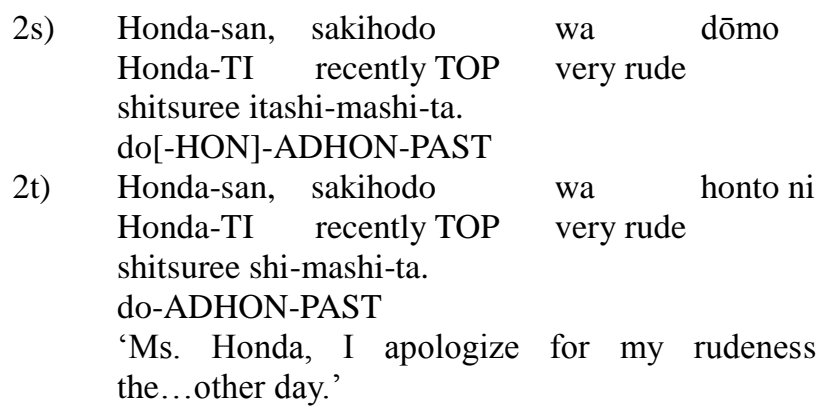

The author emphasizes that a mere use of honorific phrases is insufficient if one's voice and body language do not match with what is being said. The author also suggests that along with honorifics, use of verbal strategies like cushion words, question forms and stylistic alternation is a part of business manner. The use of cushion phrases to make an expression polite is also illustrated.

\section{2u) shitsuree desu ga, o-ikutsu desu ka? Rude COP but HP-how-old COP QM 'Excuse me but, how old are you?'}

The study brings out the importance of incorporating these aspects of the language when training people for business purposes as well as for the use of language in day to day life. The application of pragmatic theories in teaching professional use of language even to native speakers is shown to be of great importance. 


\section{Summary}

The available literature in Japanese politeness shows that the issues that are being discussed include a description of the use of honorifics in Japanese and how these forms are different from their description in western studies on universality, but in some discussions, these forms are explained as a part of the universal politeness theory based on 'face.' The issues in literature also include the significance of looking at the use of honorifics in socio-historical perspectives to have a better understanding of its use in modern Japanese. Japanese female speech is studied and described in great depth as this form was considered to be the carrier of traditional and cultural ideology of the nation [19]. The literature on honorifics shows that there have been several studies to test whether Japanese follows the universal politeness theory based on 'face.' However, we lack investigations that are representations of the use of honorific forms, especially in terms of intergenerational variation.

\section{Cross-Cultural Studies}

Reference [22] presents a sociolinguistic account of the use of greetings as politeness formulae in Syrian Arabic, American English and other languages including a short discussion on the use of greeting gestures among animals. The author uses examples from secondary sources and from personal experiences and discusses synchronic and diachronic variation in the use of greetings with a short section on the acquisition of politeness formulae. The conclusion of the study gives an outline of the requirement of a study on the variation in the structure and use of politeness formulae.

The author in [23] focuses on cultural variability just as the title of the paper "Different cultures, different languages, different speech acts" suggests. The author shows the variation in the use of imperatives, questions and conditionals in English, Polish and Australian English, which potentially leads to misunderstanding between native speakers and foreigners. The author suggests that "a linguistic study of culture specific speech acts has a great deal to contribute" to the domain of multicultural education in order to eliminate cultural clashes.

In [24], the author investigates the correlation in the use of indirectness in requesting with the degree of politeness, using data from English and Hebrew. Using the CCSARP (Cross-cultural Speech Act Realization Program) model, the author shows that a higher degree of indirectness does not necessarily make a request more polite, and an amount of pragmatic clarity is required for the request to be communicated. This is the reason that hints were considered to be impolite because they lacked pragmatic clarity. On the other hand, direct requests were considered impolite as they lacked a concern for 'face' but were still considered to be more polite than hints as they had pragmatic clarity. The conventional indirect requests were taken as the most polite forms of requests.

The author in [25] discusses the current issues and scope for further studies in linguistic politeness based on the available literature. The theme for discussion was divided into "strategic use of politeness for conflict avoidance and social indexing; social and psychological factors determining politeness; the linguistic enactment of politeness; the impact of discourse type on politeness; counterpart of politeness, i.e. rudeness". This study reviews all the available literature until its given year of publication and suggests that we still need a great number of studies on politeness in different languages that we have not yet studied. Apart from this, there is a need for more cross-cultural studies in all the four themes discussed by the author to add to the understanding of linguistic politeness.

The author in [26] emphasizes the importance of situational assessment of the situation given in discourse completion tests. The author uses the data from Chinese and British English speakers in a tutor-student relationship. The result shows that with the nationality, the notion of role-relationship changes among the two groups of respondents and hence the notion of power and distance also varies for the two groups. The study emphasizes the variation of role-relationship that respondents have in their respective cultures and states that cross-cultural studies should also take this variable into account.

Reference [27], a review article on honorifics, includes studies on honorific pronouns, terms of address, politeness in language use and honorific registers. As the studies involve a discussion on the structure and use of honorifics in various languages, this review carves out the theoretical framework used to describe honorification as well as the culture-specific variability in the use of honorifics. The review states that the culture-specific register of honorifics is necessary to understand honorification in detail.

In reference [28], the author investigates the correlation in the use of indirectness in requesting with the degree of imposition of the request on the hearer. The study was based on a comparison between British English and Japanese, and the results show that more politeness strategies are employed with a higher degree of imposition of requests by speakers of both the languages. However, the difference in the use of requests in the two languages is described as a higher use of supportive moves and conventional forms by British English subjects as compared to the Japanese subjects. The Japanese subjects, on the other hand, used more direct forms of requests and fewer supportive moves. The study chooses these two languages for comparison as they were clubbed in the group of languages that use more of negative politeness strategies to avoid face-threatening acts. However, the result shows that the two requesting strategies in the two languages vary considerably and contests the grouping of the two languages into one category, based on the use of politeness strategies described as per the theory formulated in [13].

The author in [29] investigates the use of indirect strategies in Indian languages, Malay, Chinese and Japanese. The study uses data from secondary sources in available literature and presents an interpretation of the use of power pragmatics in the given languages. The results in [30] show that "... reversed pragmatics of second person pronouns, the implicit connotation of passives, the use of echoic-formation and explicator compound verbs in Indian languages; the symbolic semantics of Malay; the depoliticalisational markers in Chinese; the exclusion of second person pronouns in Japanese" are the indirect strategies used in the 
four major Asian communities. Though the study facilitates such a comparison within the languages of Asia, the use of the term "Indian languages" for only a few examples of Hindi and Tamil from a linguistically rich country like India is not justified.

The authors in [30] investigated the use of requestive hints in English and Japanese, and found that Japanese hints are more opaque than English hints. Because of a necessity for striking a balance between better pragmatic clarity and less coerciveness in requesting as presented in [24], a scope for cultural variability is shown in the result of the study. Hence, further studies exploring cross-cultural variation are shown to be significant.

The author in reference [31] raises a research question whether the use of linguistic politeness has an "east-west divide." The author uses native speaker judgment and cites examples from secondary sources. The result shows that there is a "grand strategy of politeness (GSP)," which means that we "(a) place a high value on what relates to other person and (b) place a low value on what relates to speaker." This grand strategy of politeness is argued to be universally present in all the language communities, including the eastern and western cultures.

Reference [32] compares the use of Turkish among monolingual Turkish speakers and Turkish-German bilinguals. The use of directness in requesting by these speakers was elicited using written Discourse Completion Tests (DCT). The results show that the bilinguals preferred more of indirectness than the Turkish monolinguals and this shows the influence of German on Turkish-German bilinguals. The study also hints at the significance of investigating 'opting out' cases in order to understand the issue of indirectness.

Reference [33] investigates the situational variation affecting the use of requestive behavior between native English speakers and Greek speakers who spoke English as a second language. The author used written DCT and interviews with respondents to elicit data in ten situations. The results show that there were cross-cultural similarities in the use of indirectness in many situations as the assessment of the situations showed that both the cultures used a higher percentage of direct forms in these situations. However, in other situations, there was a variation because the learners were not aware of the social reality in the situations for tuition fee and assignment. The analysis of interviews explained that the reason for this variation was that there was a difference in how imposing the native English speakers and Greek speakers found these request situations. Based on this notion, there was a difference in the use of directness in requesting by the speakers of two groups.

The available literature on cross-cultural studies shows that the discussions on comparison between the languages were carried out by following either CCSARP [34] or by the comparison in the use of morpho-lexical linguistic forms in the chosen languages. However, we do not have a comparison of these forms based on including the functions of both indirectness and honorifics. Also, there has been a great amount of comparison between non-English languages and English or other European or western languages. The popularity of such cross-cultural studies encourages one to compare two non-English languages.

\section{RESEARCH GAPS}

The discussion of the available literature on Hindi, Japanese and cross-cultural studies on other languages has shown that politeness in Hindi is an area which needs to be further explored. Since literature on Japanese politeness has raised many arguments for and against the applicability of theories on universals in politeness, we need to study languages from eastern countries to test the adequacy of the theories to describe linguistic politeness. Most studies on speech acts have not looked at honorifics when describing the directness or indirectness of requests. A combination of these aspects needs to be examined when studying linguistic politeness, which the present study has attempted to do. Since Hindi and Japanese are languages that have an inbuilt system of honorifics, a comparison in the use of linguistic politeness in the two languages would give us insights into the cultural variability within Asian communities and also on the notion of universality in politeness.

Sociologically, the literature hints at the significance of age and gender in the use of linguistic politeness. In Hindi, the available literature only suggests that there is variation based on these two variables but gives a very broad picture of the use of linguistic politeness, taking many variables at a time. Thus, we need a focused study that aims at describing the variation in the use of linguistic politeness focusing on relative age and gender. The available literature on Japanese emphasizes the distinction in the use of linguistic politeness based on gender. Various studies have given a social as well as a socio-historical account stating that females use polite language more often than males.

Research on the two communities also hints at the changes in Indian and Japanese societies. In Indian society the post-colonial developments have brought about a change as people from the lower castes have become more stable economically and are respected socially as well. The other social changes came with globalization, equal opportunities for education and industrialization in Indian society. Similarly, in Japanese society, after the Second World War, during the Meiji period, there were various social changes that took place, leading to the modernization of the society and the language. In order to understand the reflection of these social changes in the use of linguistic politeness, we need a study that combines the opinions of the native speakers along with the theories on the intergenerational variation in language. A review of studies on linguistic politeness shows that there is a need for a study focusing on the social changes shown synchronically in the present Asian society. With the social changes, there is a possibility of reduction in the gender gap in the use of linguistic politeness and changes in the notion of 'what is polite' among different generations of the speakers of the language. The study attempts to examine how language use varies with the age and gender of the interactants along with correlation of use and perception of linguistic politeness, by analyzing the linguistic forms used in request situations. An investigation of inter-generational variation in the two language communities would give insights into the social changes in the language communities. 


\section{APPENDIX}

$\begin{array}{ll}\text { ACC } & \text { accusative } \\ \text { ADHON } & \text { addressee honorific } \\ \text { HON } & \text { honorific } \\ \text { INT } & \text { interrogative } \\ \text { NOM } & \text { nominative } \\ \text { PASS } & \text { passive } \\ \text { PAST } & \text { past } \\ \text { PERF } & \text { perfect } \\ \text { PL } & \text { plural } \\ \text { POT } & \text { potential } \\ \text { PRES } & \text { present } \\ \text { TI } & \text { title } \\ \text { TOP } & \text { topic marker }\end{array}$

\section{REFERENCES}

[1] D. K. Jain, "Verbalization of respect in Hindi," Anthropological Linguistics, vol. 11, pp. 79-97, 1969.

[2] K. Misra, Terms of Address and Second Person Pronominal Usage in Hindi: A Sociolinguistic Study, New Delhi: Bahri Publications, 1977.

[3] R. N. Srivastava and I. Pandit, "The pragmatic basis of syntactic structures and the politeness hierarchy in Hindi," Journal of Pragmatics, vol. 12, pp. 185-205, 1988.

[4] R. Pandharipande, "Passive as an optional rule in Hindi, Marathi and Nepali," in South Asian Language Analysis, B. Kachru, Ed., Urbana: University of Illinois, 1979, pp. 88-106.

[5] R. S. Pathak and V. K. Jain, "Semantics of the pronominal usage in Hindi," South Asian Language Review, vol. 6, pp. 1-15, 1996.

[6] S. Nagara, "A suggestion for teaching the Japanese Keigo system," The Journal of the Association of Teachers of Japanese, vol. 11, pp. 169-182, 1976.

[7] S. Miyagawa, "Requesting in Japanese," The Journal of Association of Teachers of Japanese, vol. 17, pp. 123-142, 1982.

[8] J. R. Searle, "A classification of illocutionary acts," Language in Society, vol. 5, pp. 1-23, 1976.

[9] H. P. Grice, "Logic and conversation," in Syntax and Semantics, P. Cole and J. L. Morgan, Eds. New York: Academic Press, 1975, vol. 9, pp. 113-127.

[10] J. M. Sadock, Toward a Linguistic Theory of Speech Acts, New York: Academic Press, 1974.

[11] T. Kageyama and I. Tamiori, "Japanese whimperatives," Papers in Japanese Linguistics, vol. 4, pp. 13-54, 1975-1976.

[12] Y. Matsumoto, "Reexamination of the universality of face: Politeness Phenomena in Japanese," Journal of Pragmatics, vol. 12, pp. 403-426, 1988.

[13] P. Brown and S. Levinson, Politeness: Some Universals in Language Usage, Cambridge: Cambridge University Press, Cambridge, 1987.

[14] J. S. Smith, "Women in charge: Politeness and directives in the speech of Japanese women," Language in Society, vol. 21, pp. 59-82, 1992.

[15] M. Inoue, "Gender, language, and modernity: Toward an effective history of Japanese women's language," American Ethnologist, vol. 29, pp. 392-422, 2002.
[16] B. Pizziconi, "Re-examining politeness, face and the Japanese language," Journal of Pragmatics, vol. 35, pp. 1471-1506, 2003.

[17] A. Fukada and N. Asato, "Universal politeness theory: Application to the use of Japanese Honorifics," Journal of Pragmatics, vol. 36, pp. 1991-2002, 2004.

[18] S. Ide, "Formal forms and discernment: Two neglected aspects of linguistic politeness," Multilingua, vol. 8, pp. 223-248, 1989.

[19] W. Koyama, "Honorifics in critical-historic pragmatics: The linguistic ideologies of modernity, the national standard and modern Japanese honorifics," Journal of Pragmatics, vol. 36, pp. 2023-2054, 2004.

[20] O. Ishiyama, "A note on Matsumoto regarding Japanese verbs of giving and receiving," Journal of Pragmatics, vol. 41, pp. 1061-1065, 2009 .

[21] C. D. Dunn, "Formal forms or verbal strategies? Politeness theory and Japanese business etiquette training," Journal of Pragmatics, vol. 43, pp. 3643-3654, 2011.

[22] C. Ferguson, "The structure and use of politeness formulas," Language in Society, vol. 5, pp. 137-151, 1976.

[23] A. Wierzbicka, "Different cultures, different languages, different speech acts: Polish vs English," Journal of Pragmatics, vol. 9, pp. 145-178, 1985.

[24] S. Blum-Kulka, "Indirectness and politeness in requests: Same or different?" Journal of Pragmatics, vol. 11, pp. 131-146, 1987.

[25] G. Kasper, "Linguistic politeness: Current research issues," Journal of Pragmatics, vol. 14, pp. 193-218, 1990.

[26] H. Spencer-Oatey, "Conceptions of social relations and pragmatics research," Journal of Pragmatics, vol. 20, pp. 27-47, 1993.

[27] A. Agha, "Honorification," Annual Review of Anthropology, vol. 23, pp. 277-302, 1994

[28] S. Fukushima, "Request strategies in British English and Japanese," Language Sciences, vol. 18, pp. 671-688, 1996.

[29] J. W. Sew, "Power pragmatics in Asian languages," Language Sciences, vol. 19, pp. 357-36, 1997.

[30] C. Rinnert and H. Kobayashi, "Requestive Hints in Japanese," Journal of Pragmatics, vol. 31, pp. 1173- 1201, 1999.

[31] G. Leech, "Politeness: Is there an east-west divide?" Journal of Foreign Languages, vol. 28, pp. 1-30, 2005.

[32] S. Marti, "Indirectness and politeness in Turkish-German bilingual and Turkish monolingual requests," Journal of Pragmatics, vol. 38, pp. 1836-1869, 2006.

[33] M. Economidou-Kougetsidis, "Cross-cultural variation in requesting behaviour: Perceptions of social situations and strategic usage of request patterns," Journal of Pragmatics, vol. 48, pp. 2073-2348, 2010.

[34] S. Blum-Kulka, J. House, and G. Kasper Cross-Cultural Pragmatics: Requests and Apologies, Norwood: Ablex, 1989.

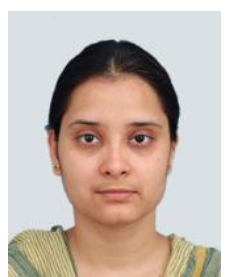

N. Kumari was born in Pupri, India on December 8 , 1983. She received her $\mathrm{PhD}$ degree in linguistics from IIT Madras, India in April 2013. Her major field of study is sociopragmatics and a comparative study of linguistic politeness in Hindi and Japanese.

She received two fellowships from the Japan Foundation for conducting her fieldwork during her $\mathrm{PhD}$. She has been teaching at University of Tsukuba as a part-time faculty since October 2013 and became a full-time assistant professor since April 2015.

Dr. Kumari is a lifetime member of Linguistic Society of India and a member of Pragmatic Society of Japan. 